\title{
Acquired colour defects under restricted viewing time: a new diagnostic technique?
}

\author{
S. P. TAYLOR \\ From the Department of Optometry, UWIST, Colum Drive, Cardiff CF1 3EU
}

SUMMARY The effect of reduced viewing time on classification of colour vision by means of the City University Colour Vision Test is investigated in sufferers from diabetes and optic neuritis. The results suggest that patients with these conditions give non-normal responses when viewing time is reduced to $3.75 \mathrm{~m}$. It may be possible to use the response obtained to diagnose the presence of ocular disease.

Most studies of acquired defects of colour vision corroborate the observations of the German ophthalmologist/physiologist Kollner ${ }^{1}$ published in 1912. Lesions of the outer layers of the retina give rise to a yellow-blue defect, while lesions of the inner retinal layers and of the optic nerve give rise to defects in the red green. Verriest ${ }^{2}$ has proposed 4 principal types of acquired colour vision deficiency. These are as follows.

(i) Type A, where no prominent axis of deterioration can be found. This occurs, for example, in some cases of macular cysts and toxic amblyopia.

(ii) Subtype I R-G defect (retinal group). This is a protan-type defect which is suggested as being due to involvement of the macular cones and is often associated with a central scotoma. The defect has been described by Marré ${ }^{3}$ as principally a disturbance of the blue mechanism with some equal impairment of the red and green mechanisms and is characterised by a lowering of hue discrimination throughout the spectrum. The type of defect occurs in some lesions involving the macular area, such as juvenile macular degeneration.

(iii) Subtype II $R-G$ defect (neural group). This is a deutan-type defect that may be associated with impairment in conduction of the visual signal. Marré ${ }^{3}$ has suggested that this group is a combined disturbance of the blue, green, and red mechanisms. There is often a concomitant blue-yellow defect associated with this subtype, ${ }^{4}$ and the defect occurs especially in diseases of the optic nerve and of the anterior part of the optic pathway.

(iv) A type III B-Y defect. This is the most common type of acquired defect of colour vision and is a form

Correspondence to Dr S. P. Taylor. of tritan defect. Subjects exhibit one neutral band at $570 \mathrm{~nm}$ and a second at about $470 \mathrm{~nm}$. The defect is similar to the mesopisation B-Y defect found in normal subjects. According to Marré ${ }^{3}$ only the blue mechanism seems to be affected, although subjects show a Nagel anomaloscope setting shifted toward the longer wavelengths. Often the defect is accompanied by impairment of vision in low illumination and poor dark adaptation. The defect is associated with pigment degenerations of the retina.

This paper deals with a study on the effect of restricted viewing time on classification of colour vision in cases of optic neuritis and cases of diabetes. There seems to be no information on the effect of reduction of viewing time on the colour performance in cases of acquired deficiencies of colour vision. There has, however, been some work that suggests poor temporal resolution in multiflash campimetry in multiple sclerosis. ${ }^{56}$ Studies on the effect of restricted viewing on colour performance in colour-normal subjects suggest a blue-yellow type defect is produced that may be classified as tritan on the City University Colour Vision Test ${ }^{7}$ and abnormal on the Moreland anomaloscope. ${ }^{8}$ This induced defect is probably due to the integration differences in signal time in the red-green and blue-yellow system ${ }^{910}$ (Sperling, H. G., personal communication). If this is true, then it is likely that there will be a difference in the colour performance of colour-defective and colour-normal subjects. A recent study has shown that for congenital colour-defective subjects the same blue-yellow is superimposed on the primary red-green defect under conditions of reduced viewing time. ${ }^{12}$ This study investigates the effect of restricted viewing in cases of disease that may be associated with changes in colour vision. 
Extensive studies of the colour vision of diabetics have been made. ${ }^{212-14}$ The results from all these studies show that diabetics develop a type III blueyellow defect. Lakowski et al. ${ }^{13}$ showed that attempts to predict the colour vision deterioration from clinical variables such as the duration of diabetes, the year of onset, and the level of blood-sugar control were unsuccessful. The reports also show that red-green losses as demonstrated on the anomaloscope are small and that no midmatching ranges are outside the $\pm 3 \cdot 00 \mathrm{SD}$ limits of the normal population. ${ }^{12}{ }^{13}$ This factor is very important in the present study, where an attempt is made to investigate the effect of reduced viewing time on a condition in which a colour disorder is due to a retinal problem producing a blue-yellow defect.

Optic neuritis is a condition that produces a type II red-green defect. Primarily it affects the optic nerve, and causes include inflammatory conditions such as meningitis, demyelinating diseases such as multiple sclerosis, and vascular disease. The clinical presentation is of a reduction in visual acuity and often a central scotoma. Although a blue-yellow type defect has been reported, ${ }^{14}$ most authors agree that a type II red-green defect occurs in optic neuritis irrespective of the underlying cause. ${ }^{15-19}$ The defect may persist even after the visual acuity has returned to normal. ${ }^{162021}$ It has been suggested ${ }^{22}$ that the redgreen defect is atypical in the acute phase of optic neuritis but typical in the atrophic phase, a suggestion that would explain the reports of the existence of 2 types of defect.

\section{Material and methods}

Patients were tested with the City University Colour Vision Test (CUCVT). ${ }^{2324}$ by the arrangement shown in Fig. 1. A colour balanced source of colour temperature $6500 \mathrm{~K}$ and average intensity of 600 lux was used to illuminate the plates of the CUCVT. The viewing distance was held constant at $25 \mathrm{~cm}$ and a highly reliable Compur type camera shutter used to control the exposure times. The shutter could be set to give viewing times of $3 \cdot 75,5 \cdot 5,9,16 \cdot 5,31$, $60,120,250,500 \mathrm{~ms}, 1$ second, and open viewing. When the shutter was closed, fixation was maintained by an incomplete cross which did not interfere with the colour plate when the shutter was open as shown in Fig. 1.

The CUCVT was chosen as the most suitable for the present study. It presents 4 test dots around a single standard dot and the subject is required to give a single response (top, bottom, left, or right), indicating which of the surround dots most closely matches the colour of the central reference dot. There are 10 test plates in the book, all of which are different. Each test plate provides a single unique response corresponding to the protan, deutan, tritan, or normal responses. The design is such that ideally one of each of the surrounding test dots lies along the confusion line of protan, deutan, and tritan observers, which pass through the co-ordinates of the central standard patch. The fourth patch, while lying off these loci, lies chromatically near to the standard.

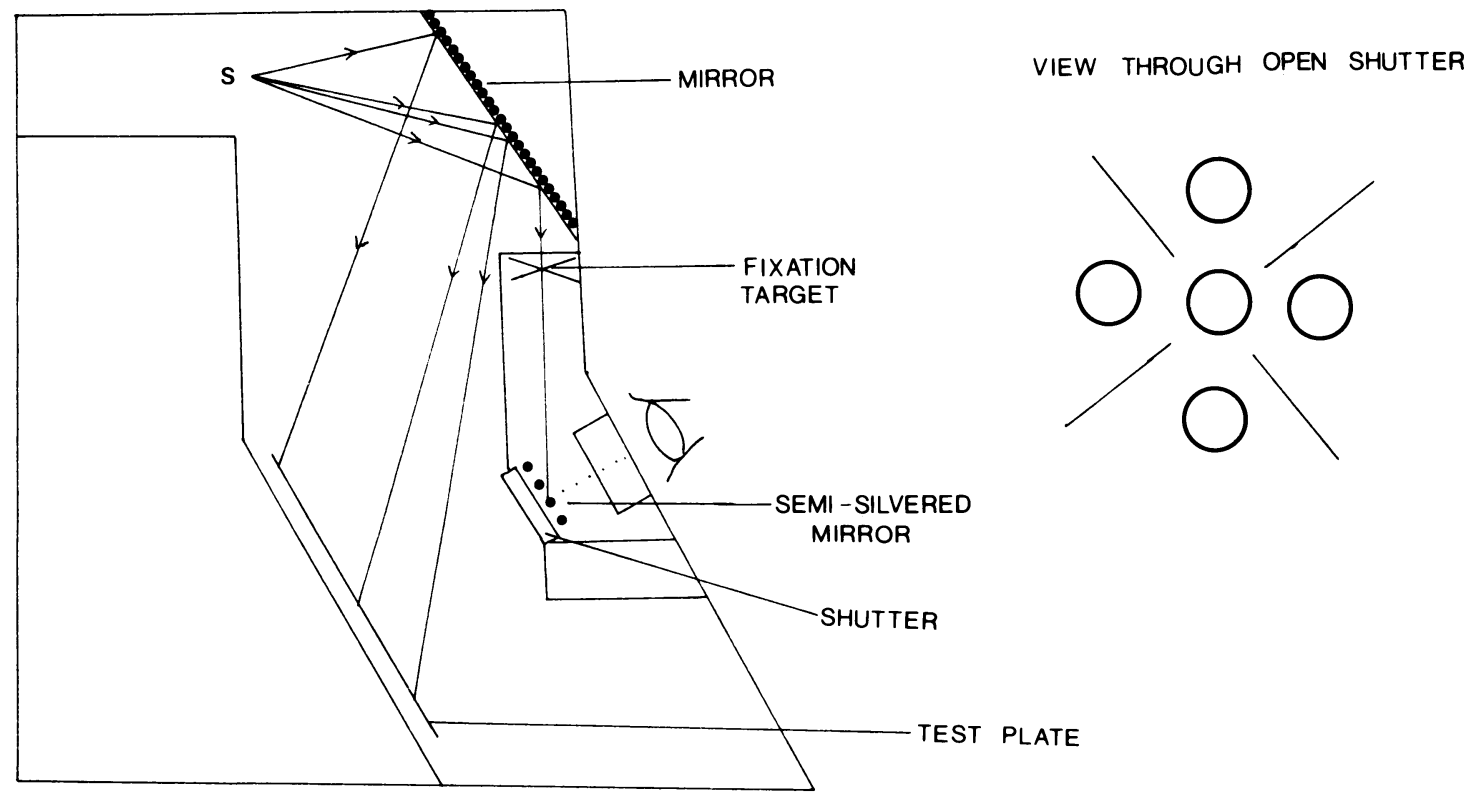

Fig. 1 Apparatus for illuminating and viewing the City University Colour Vision Test. 
The test is based on the colour chips of the D-15 colour test ${ }^{25}$ and on this basis it is not a screening test but a test to detect moderate and severe colour defectives. In the present arrangement each coloured dot subtends an angle of $1^{\circ} 50^{\prime}$, and the entire array of coloured patches on each plate subtends an area of approximately $9^{\circ}$ of visual angle.

All subjects were tested monocularly in open viewing on the apparatus for each eye using the standard test procedure of the CUCVT. The test was then repeated but with viewing time restricted to $3.75 \mathrm{~ms}$. Subjects were adapted to a room illumination of 300 lux prior to each measurement.

If the subjects failed any plates at a particular viewing time, those plates were re-examined at the next longest exposure. This was repeated until all plates were seen correctly.

\section{SUBJECTS}

Diabetes. Six subjects were studied. Three showed ophthalmoscopic evidence of retinopathy, haemorrhage, and exudates, and 3 showed no evidence of retinopathy. Their ages ranged from 22 to 48 years, and duration of diabetes ranged from 18 months to 30 years.

Optic neuritis. Five subjects were studied-4 women and $1 \mathrm{man}$. The man, 37 years of age, suffered from bilateral chronic optic neuritis of unknown aetiology. His acuity was reduced to $6 / 24 \mathrm{RE}, 6 / 18$ LE, and N10 at near, and he had suffered recurrent bouts of optic neuritis since the age of 11 years. Three of the women, aged 29,35 , and 60 , suffered from unilateral optic neuritis, one for the second time, and had been diagnosed as sufferers from multiple sclerosis. The fourth woman, age 44 , showed unilateral papillitis of undiagnosed origin.

\section{Results}

It has been shown in colour-normal observers that reduction in viewing time induces a tritan-like error on the CUCVT. All observers showed the effect, and $48 \%$ of the responses were tritan, no other responses type was observed. ${ }^{7}$

Diabetic subjects who are colour normal under conditions of unrestricted viewing showed the tritantype effect observed with normal subjects when viewing time was reduced. The percentage of tritan errors was similar to that for normal observers. The group showing ophthalmoscopic signs of retinopathy gave a similar response to the normals and the nonretinopathy group, in that the responses were of the tritan type and the percentage of errors was similar to that in the other groups. The difference, however, was that no response at all could be obtained at the fastest shutter speed. Some of the subjects had to have the shutter speed reduced to an integrated time of $60 \mathrm{~ms}$ before any response could be achieved.

All optic neuritis subjects, also colour-normal in unrestricted viewing, showed a varied response with restricted viewing time in their affected eyes, as shown in Fig. 2. Two subjects were unable to perform the tests at rapid shutter speeds, one suffering from chronic optic neuritis and the other from active papillitis. One other subject could not make any response between a shutter speed of $30 \mathrm{~ms}$ and an
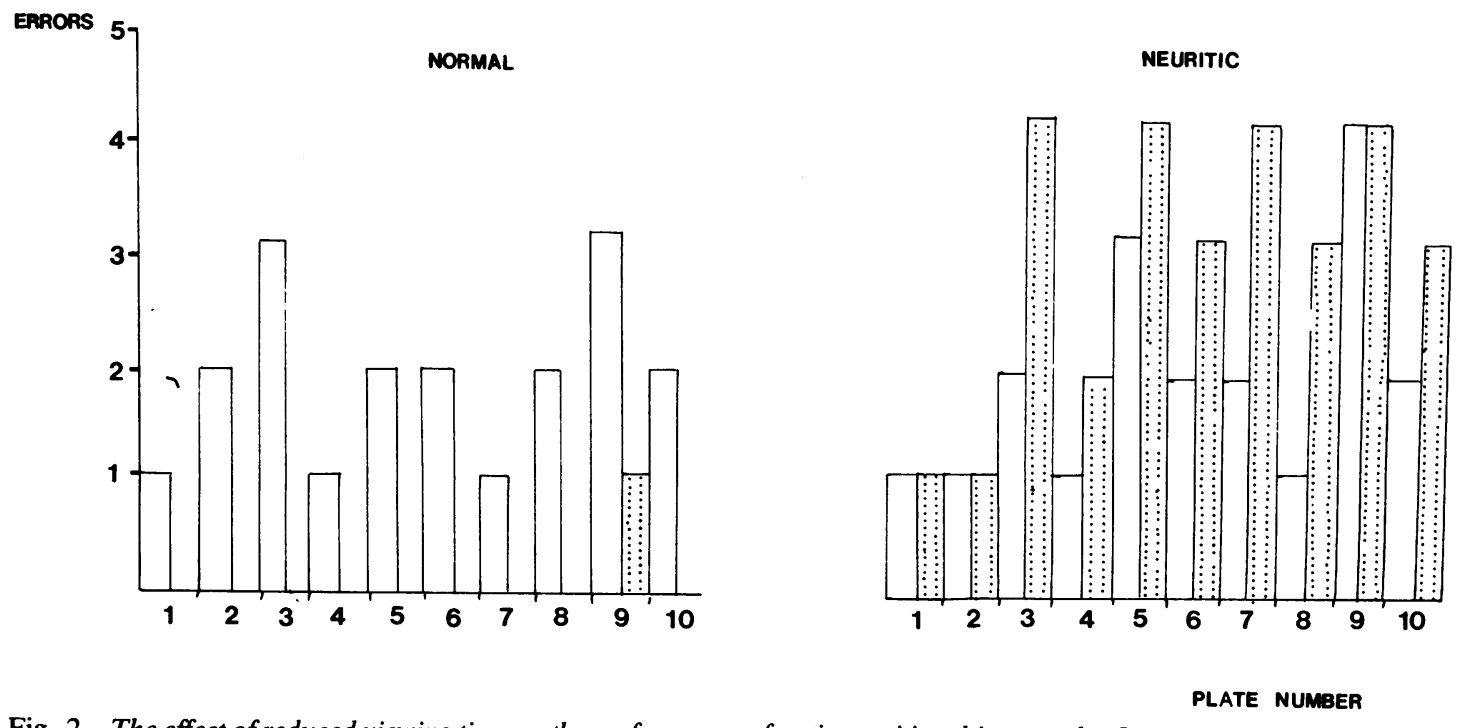

Fig. 2 The effect of reduced viewing time on the performance of optic neuritis subjects on the City University Colour Vision Test. Tritan defect Red/green defect 
open viewing situation, complaining that the target became 'white'. The results on the left in Fig. 2 are for the 4 normal eyes and the results on the right for the 6 neuritic eyes. If a subject gave a tritan response and a red-green response to a particular plate, then both responses are recorded, hence the total errors for some plates may exceed the number of observers. For example, plate 9 suggests 8 errors; this represents some subjects giving both a tritan and a red-green response to this plate at different viewing time. All subjects gave the same response patterns, although the plates that were failed differed. The histogram is prepared in this way to allow inclusion of results for those subjects who did not see the plates until longer viewing times.

\section{Discussion}

In both optic neuritis and diabetes the subjects are unable to respond on the CUCVT when the condition is actively affecting the visual pathway. In optic neuritis this occurs in the neural transmission, whereas in diabetes it is likely to occur at a lower level, i.e., within the retina itself. A difference occurs in the responses in the 2 conditions in that the diabetic subjects show only the blue-yellow defect found in normal observers, whereas the neuritic group shows a red-green defect superimposed on the time-induced blue-yellow defect.

The neuritic group show that a non-normal response is recorded even after the attack of neuritis and after the symptoms have disappeared. This could indicate the presence of neural damage that may not normally recover. It implies that detection of neuritis or of a previous attack might be possible by using the CUCVT with restricted viewing time.

The diabetic group show no difference from the normal response under viewing times restricted to $3.75 \mathrm{~ms}$ unless ophthalmoscopic evidence is found of retinopathy. When active neural lesions are evident -i.e., when retinopathy occurs - the subjects are unable to perform the CUCVT at this short exposure. In such cases, however, once a response is obtained by increasing the viewing time, it appears to be the same as the time-dependent effect in normals.

The results for the neuritic group are shown to be different in the affected and the unaffected eye, suggesting a very definite effect. Controls for the diabetic group cannot be so easily found, but results do compare very well with results for normal groups. It is important that further investigation of the diabetic condition is made. It may be that the appearance of the colour loss coincides with the appearance of retinal changes, giving an easy and nonintrusive method of detecting early changes.

It seems that the use of restricted viewing time may prove to be a useful diagnostic technique for ocular pathology. Further studies are necessary, however, before its true value can be defined.

\section{CONCLUSION}

Use of the CUCVT under conditions of restricted viewing time induces a non-normal response in cases of optic neuritis. In diabetes where there is ophthalmoscopic evidence of retinopathy the response of a normal eye is obtained but at longer viewing times. These results suggest that the use of restricted viewing time for colour vision testing is a useful diagnostic technique.

My thanks to Dr J. M. Woodhouse for her comments on the draft script and to Professor J. Christopher Dean-Hart and Mr Campbell of the Bristol Eye Hospital for allowing the use of facilities within their clinics.

\section{References}

1 Kollner H. Die Storungen des farbensinnes. Ihre Klinische bedentung und Ihre Diagnose. Berlin: Karger, 1912.

2 Verriest G. Further studies on acquired deficiency of colour discrimination. J Opt Soc Am 1963; 53: 185-95.

3 Marré M. The investigation of acquired colour vision deficiencies. Hilger, London: 1973; 73A.

4 François J, Verriest G. On acquired deficiencies of colour vision. Vision Res 1961; 1: 201-19.

5 Brussell EM, White CW, Bross M, Mustillo P, Borenstein M. Multi-flash campimetry in multiple sclerosis. Curr Eye Res 1981/82: 1: 671-7.

6 Mason RJ, Snelgar RS, Foster DH, Heron JR, Jones RE. Abnormalities of chromatic and luminance critical flicker frequency in multiple sclerosis. Invest Ophthalmol Visual Sci 1982; 23: 246-52.

7 Taylor SP. A time induced tritan effect. Vision Res 1983; 23: 745-8.

8 Taylor SP. The effect of restricted viewing time on mid-match points for colour normal observers on the Moreland and Pickford Nicolson anomaloscopes. To be published.

9 Krauskopf J. Interaction of chromatic mechanisms in detection. Mod Probl Ophthalmol 1974; 13: 92-7.

10 Taylor SP. A brief review of colour latency. Optician 1981; 181: $11,12,25$

11 Taylor SP. The effect of restricted viewing time on the performance of colour defectives on the City University Colour Vision Test. Ophthalmic Physiol Opt in press.

12 Kinnear PR, Aspinall PA, Lakowski R. The diabetic eye and colour vision. Trans Ophthalmol Soc UK 1972; 92: 69-78.

13 Lakowski R, Aspinall PA, Kinnear PR. Association between colour vision losses and diabetes mellitus. Ophthalmic Res 1973; 4: $145-59$.

14 Ohta Y. Studies on acquired anomalous colour vision Colour 69. Gottingen. Mustenschmidt, 1970: 88-96.

15 François J, Verriest G. les dyschromatopsies acquises. Ann Oculist (Paris) 1957; 190: 713-46.

$16 \mathrm{Cox} \mathrm{J}$. Colour vision defects acquired in diseases of the eye $\mathrm{Br} \mathrm{J}$ Physiol Opt 1960; 17: 195-216.

$17 \mathrm{Cox} \mathrm{J}$. Colour vision defects acquired in diseases of the eye $\mathrm{Br} \mathrm{J}$ Physiol Opt 1961; 18: 3-32, 67-98.

18 François J, Verriest G. Nouvelles observations de deficiencies acquises de la discrimination chromatique. Ann Oculist (Paris) 1968; 201: 1097-114.

19 Nikoselainen E. Symptoms, signs and early course of optic neuritis. Acta Ophthalmol (Kbh) 1975; 53: 254-71.

20 Scheibner $H$, Thranberend $C$. Colour vision in a case of neuritis retrobulbaris. Mod Probl Ophthalmol 1973; 13: 339-4. 
21 Wilberger HGH, van Lith GHM. Colour vision and visual evoked response in the recovery period of optic neuritis. Mod Probl Ophthalmol 1976; 17: 320-4.

22 Kurata K. Study on the colour discrimination of subjects with acquired anomalous colour vision. Nippon Ganka Gakkai Zasshi 1965; 69: 1998-2006.
23 Fletcher RJ. A modified D-15 test. Mod Probl Ophthalmol 1972; 11: $22-4$.

24 Fletcher RJ. The City University Colour Vision Test. London: Keeler Instruments Ltd, 1975.

25 Farnsworth D. The Farnsworth-Munsell 100 hue and dichotomous tests for colour vision. J Opt Soc Am 1943; 33: 568-78. 